\title{
XIX.
}

\section{Ueber das Cocaïn, eine organische Base in der Coca.}

\author{
Schreiben voll
}

\section{Fr. Wöhler an W. Haidinger.}

(Im Auszuge aus d. Sitzungsber. d. Kais. Acad. d. Wissensch. zu Wien. 1800.)

\section{Vorwort von Haidlinger.}

Indem ich der hochverehrten mathematisch-naturwissenschaftlichen Classe das werthvolle Schreiben meines hochverehrten Freundes Wöhler überreiche, erlaube ich mir einige Worte über den Antheil zu sagen, welchen ich selbst dabei genommen, und der Veranlassung war, dass es mir gegönnt ist die erste Kunde über die Eigenschaften dieses merkwürdigen Körpers, des Cocaïns, vorzulegen. Schon während der Vorbereitung für die Erdumsegelung hatte Wöhler in einem Schreiben den Wunsch ausgesprochen, von dieser so vielfältig besprochenen Pflanze durch die "Novara" Material zur chemischen Untersuchung zu erhalten. Herr Dr. Scherzer hatte in einer Sitzung (am 7. April, Mittheilungen 1857, Bd. I, St. 130) der k. k. geographischen Gesellschaft die Erwerbung von Coca zu Versuchen aller Art als eine der Aufgaben hingestellt. Während der Zeit der Reise glaubte ich der unmittelbare Bezur könnte rascher noch zum Ziele führen, und wurde dabei auf das Freundlichste von unserem hochverehrten correspondirenden Mitgliede IIerrn Dr. J. J. v. Tschudi unterstützt, der selbst zu diesem Zwecke an seinen Freund Hern Mariano de Rivero, damals Generalconsul der Republik Peru in Brüssel, schrieb. Der leider zu früh eingetretene Tod dieses hochverdienten Mannes unterbrach die eingeleiteten Schritte. Als aber Herr Dr. Scherzer im Mai 1859 die "Novara“ in Valparaiso verliess, und über Lima und Panama nach Europa gring, anstatt die Fregatte um das Cap Horn herum zu hegleiten, so erwarb er nicht 
nur eine gute Partie Coca, sondern er sah auch die Ungelegenheit, einen Theil als Passagiergut mit sich zu führen, nicht für zu gross an, um sie nur ja gewiss frisch und im guten Zustande nach Europa zu bringen. Anfangs September kam Dr. Scherzer in Wien an. Am 13. holte ich ihn in seiner Wohnung ab, wir nahmen die Kiste Coca mit in die k. k. geologische Reichsanstalt. Dort wurde sie eröffnet, die äussere Holzkiste und sodann das innere verlöthete Weissblechbehältniss. Es wurde ein Theil des Inhaltes herausgenommen zur Uebergabe an die Herren k. k. Regierungsrath Prof. K. D. Schroff, k. k. Prof. Redtenbacher u. s. w., und ohne den Inhalt an Blättern auszuleeren, sandte ich den Rest, der Schätzung nach etwas mehr als die Hälfte des Ganzen (einer "Arroba" $=20,573$ Wiener Pfund) an meinen hochverehrten Freund Wöhler nach Göttingen ab. Durch die Erdumsegelung der $\mathbf{k} . \mathbf{k}$. Fregatte "Novara" unter. unseres trefflichen, unternehmenden Dr. Scherzer's aufmerksamer Sorgfalt, ging auf diese Weise der Wunsch unseres Wöhler in Erfüllung. Nur wenige Wochen später, am 9. October, sandte mir auch Herr v. Tschudi ein Packetchen Coca, etwa ein Pfund, das er selbst von seiner letzten südamerikanischen Reise mitgebracht, und das ich gleichfalls an Freund Wöhler spedirte. Auch die von einem bolivianischen Chemiker dargestellte "Cocaïna" hatte Herr v. Tschudi an Wöhler gesandt, die sich aber, wie Letzterer fand, als Gyps erwies, wie dieses Herr v. Tschudi selbst in einer früheren unserer Sitzungen mittheilte. So war es mir vergönnt, gewissermaassen als verbindendes Glied zwischen den mit Wien und dem Kaiserreiche zusammenhängenden Unternehmungen einerseits und dem Orte der chemischen Untersuchung Göttingen andererseits zu wirken, ohne doch selbst einen Antheil von Arbeit als eben diese Vermittlung mein nennen zu dürfen. Aber gerade diese ist es, welche meinen hochverehrten Freund Wöhler bestimmte, an mich sein Schreiben zu richten, wofür ich ihm hier meinen innigsten Dank darbringe. 
Göttingen, am 28. Februar 1860.

Die wunderbaren physiologischen Wirkungen, welche von der Coca, den Blättern von Erythroxylon Coca, berichtet werden, und welche diese Pflanze in Südamerika zu einem Gegenstand der Cultur und des Handels gemacht haben, liessen schon im Voraus darin einen besonderen organischen Körper als das eigentlich wirksame Princip vermuthen, von dem mit grosser Wahrscheinlichkeit anzunehmen war, dass er zur Classe der organischen Basen gehören werde. Auch sind zur Auffindung dieses wirksamen Bestandtheiles bereits verschiedene Versuche gemacht worden, von denen aber keiner zu einem positiven Resultate geführt hat, vielleicht weil zu kleine Mengen der Blätter oder zu alt gewordenes Material zur Untersuchung genommen wurden. Diese letzteren Schwierigkeiten sind nun durch die grosse Quantität Coca beseitigt worden, welche Sr. k. k. Apostolischen Majestät Fregatte „Novara“ von ihrer Reise um die Erde mitgebracht, und wovon mir eine Partie durch die Direction der k. $k$. geologischen Reichsanstalt freundlichst zugesendet worden ist. Ueberhäuft mit $\mathrm{zu}$ vielen anderen Obliegenheiten, war ich nicht im Stande, diese interessante Arbeit selbst vorzunehmen. Ich übertrug sie einem der Assistenten am hiesigen Laboratorium, Herrn Niemann, der, vollkommen geübt in dergleichen Untersuchungen, dieselbe mit grossem Geschick und rühmlichster Ausdauer ausgeführt hat, und dem es gelungen ist in der Coca in der That eine eigenthümliche, krystallisirbare organische Base zu entdecken, der nach dem üblichen Sprachgebrauch der Name Cocain beigelegt werden kann. Die Arbeit ist indessen noch weit entfernt beendigt zu sein, denn wenn auch das Dasein und die Eigenthümlichkeit des Cocaïns feststeht, so ist doch seine Zusammensetzung noch nicht sicher ausgemittelt, und es sind über die zweite Hauptfrage, die Art seiner physiologischen Wirkungen, die vielleicht $\mathrm{zu}$ wichtigen medicinischen Anwendungen führen, die beabsichtigten Beobachtungen an Thieren und Menschen noch nicht gemacht, und es sind die übrigen Bestandtheile der Planze, worunter sich eine eigenthümliche Gerbsäure zu befinden scheint, 
noch nicht näher untersucht. Die gegenwärtige Mittheilung ist also nur eine vorläufige, mit dem Vorbehalte, der kaiserlichen Academie später die vollständigen Resultate in einer ausführlichen Abhandlung vorlegen zu dürfen.

Zur Darstellung des Cocaïns wandte Herr Niemann, nach mancherlei fruchtlosen Versuchen, das folgende Verfahren als das zweckmässigste an: Die fein zerschnittenen Cocablätter wurden mehrere Tage lang mit Alkohol von 85 p.C., dem etwas Schwefelsäure beigemischt war, digerirt, die entstandene dunkelbraun-grüne Lösung ausgepresst, filtrirt, und darauf mit Kalkhydrat versetzt. Hierdurch wurden unter anderem ein Theil des Chlorophylls und ein Wachs ausgeschieden, welches aus dem Niederschlage farblos dargestellt werden konnte. Die davon abfiltrirte Flüssigkeit, die schwach alkalisch reagirte, wurde mit Schwefelsäure neutralisirt, der grösste Theil des Alkohols davon abdestillirt und der Rest desselben im Wasserbade abgedunstet. Der Rückstand wurde mit Wasser vermischt, wodurch eine schwarzgrüne, halbflüssige Masse abgeschieden wurde, welche viel Chlorophyll enthielt, während sich eine gelbbraune Lösung bildete, die von ersterer abfiltrirt werden konnte. Diese Lösung enthält nun das Cocaïn als schwefelsaures Salz. Sie wurde mit kohlensaurem Natron versetzt, wodurch die Base in noch unreinem Zustande als brauner Niederschlag gefällt wurde. Der Niederschlag wurde mit Aether behandelt, welcher das Cocaïn mit Zurücklassung der Unreinigkeiten auföste. Nach dem $\Lambda$ bdestilliren des Aethers blieb es in Gestalt einer eigenthümlich riechenden, noch grünlichgelb gefärbten firnissähnlichen Masse zurück, in der sich aber bald concentrisch-strahlige Krystallisationen zu zeigen anfingen. Durch wiederholte Behandlung mit Alkohol wurde es geruch- und farblos erhalten. Am besten krystallisirte es aus der Alkohollösung, wenn diese mit so viel Wasser versetzt wurde, dass ein Niederschlag zu entstehen anfing.

Das Cocaïn krystallisirt in farb- und geruchlosen kleinen Prismen. In Wasser ist es schwer, in Alkohol leichter und sehr leicht in Aether löslich. Seine Auflösung in Alkohol reagirt stark alkalisch und besitzt einen eigenen 
bitterlichen Geschmack. Dabei übt es auf die Zungennerven die merkwürdige Wirkung aus, dass die Berührungsstelle nach wenigen Augenblicken wie betäubt, fast gefühllos wird. Es schmilzt schon bei $98^{\circ} \mathrm{C}$, und erstarrt dann wieder strahlig-krystallinisch. Stärker erhitzt, färbt es sich erst röthlich und zersetzt sich dann unter Entwickelung eines ammoniakalischen Geruchs. Nur ein sehr kleiner Theil scheint sich dabei unzersetzt zu verflüchtigen. Auf Platinblech erhitzt, verbrennt es mit leuchtender Flamme ohne Rückstand.

Das Cocaïn neutralisirt die Säuren vollständig, indessen scheinen die meisten Salze nicht leicht zu krystallisiren, sondern lange im amorphen Zustande zu verharren. Am leichtesten, feinstrahlig krystallisirt das salzsaure Salz. Salzsaures Gas wird von trocknem Cocaïn unter so starker Wärmeentwickelung gebunden, dass letzteres dabei schmilzt.

Die Lösung des salzsauren Cocaïns ist durch folgende Reactionen charakterisirt.

Kaustische und kohlensaure Alkalien fällen daraus weisses Cocaïn, löslich im Ueberschuss von Ammoniak, nicht in dem von fixem Alkali.

Goldchlorid bildet einen hellgelben, dickflockigen Niederschlag, löslich in heissem Wasser, noch leichter in heissem Alkohol, woraus das Doppelsalz in glänzenden gelben Blättchen auskrystallisirt. Sehr merkwürdig ist sein Verhalten beim Erhitzen, indem es dabei ein Sublimat von Benzoësäure giebt.

Platinchlorid bildet einen gelbbraunen, flockigen Niederschlag, der rasch krystallinisch wird.

Quecksilberchlorid fällt eine weisse amorphe Verbindung.

Phosphormolybdänsäure fällt weissgelb, flockig.

Pikrinsäure schwefelgelb, flockig, bald harzähnlich werdend.

Gerbsäure bewirkt für sich keine Fürbung, aber auf Zusatz von Salzsäure entsteht sogleich ein dichter graulicher Niederschlag, der ebenfalls sich bald harzähnlich zusammenballt.

Jodwasser bewirkt einen kermesbraunen Niederschlag. 